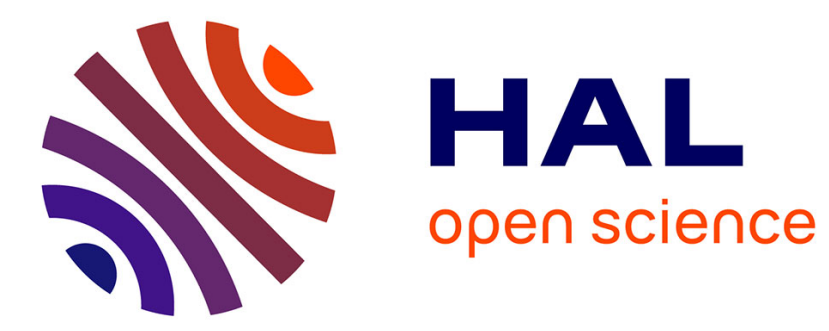

\title{
RobAFIS student competition: from systems engineering to the engineering of one system Jean-Claude Tucoulou, David Gouyon
}

\section{To cite this version:}

Jean-Claude Tucoulou, David Gouyon. RobAFIS student competition: from systems engineering to the engineering of one system. INSIGHT - International Council on Systems Engineering (INCOSE), 2013, 16 (4), pp.7-10. hal-00918381

\section{HAL Id: hal-00918381 \\ https://hal.science/hal-00918381}

Submitted on 16 Dec 2013

HAL is a multi-disciplinary open access archive for the deposit and dissemination of scientific research documents, whether they are published or not. The documents may come from teaching and research institutions in France or abroad, or from public or private research centers.
L'archive ouverte pluridisciplinaire HAL, est destinée au dépôt et à la diffusion de documents scientifiques de niveau recherche, publiés ou non, émanant des établissements d'enseignement et de recherche français ou étrangers, des laboratoires publics ou privés. 


\title{
RobAFIS student competition:
}

\section{From Systems Engineering to the engineering of one system}

\author{
Jean-Claude Tucoulou ${ }^{1}$ (jeanclaude.tucoulou@incose.org) \& \\ David Gouyon ${ }^{2,1}$ (david.gouyon@univ-lorraine.fr)
}

This paper presents the RobAFIS competition which has been organized every year since 2006 by AFIS, the French chapter of INCOSE. Each year this project benefits from previous edition feedback, in order to continuously improve the educational value of the event. Beyond the interest of competition, the RobAFIS repository is increasingly used as a model for the deployment of a Systems Engineering education supported by a project.

\section{OBJECTIVES}

RobAFIS enhances AFIS action, offering educational and research institutions an operation to better understand and develop the use of systems engineering best practices, as recommended and formalized by AFIS. The recommended reference document for RobAFIS is the book "To discover and understand Systems Engineering" [1].

The main objective of RobAFIS is to highlight the benefits of basing systems engineering education on a project life cycle realization: a full life cycle including the implementation of an operational system, deployed by a client, in a real environment.

\section{A COMPETITION IN A PEDAGOGICAL FRAMEWORK}

RobAFIS is both a comparative assessment between robots presented by competing teams, and an educational operation which purpose is to lead student teams to implement collaboratively Systems Engineering approach and methods to design a solution, and write a Development Document.

Students and their supervising teachers have the opportunity to exchange with the jury AFIS expert members, working in industry or teaching Systems Engineering. During development, these experts answer, via a FAQ page on a RobAFIS dedicated collaborative space [3], questions about: competition rules and organization, technical or methodological issues related to stakeholder requirements or to the development document.

After the competition, individual feedbacks are proposed to teams, during which jury members give detailed information about the evaluation, the methods and tools used, and about robot behavior and performances. The jury gives an educational dimension to its answers and comments. These feedbacks enable the comparison between learners and practitioners points of view.

\section{ROBAFIS: A COMPETITION BETWEEN TEACHING INSTITUTIONS}

This competition is open to bachelor or master degrees students, in an engineering discipline (system, electronics, software, mechanical, hydraulic, etc.). Since the beginning of RobAFIS in 2006, about twenty different institutions participated at least one time, with an average of ten registered teams each year.

\footnotetext{
${ }^{1}$ Association Française d'Ingénierie Système

${ }^{2}$ Centre de Recherche en Automatique de Nancy

Université de Lorraine, CNRS

Boulevard des aiguillettes, BP 70239, 54506 Vandoeuvre les Nancy, France
} 


\section{ROBAFIS: A PROJECT - AN ORGANISATION}

\subsection{PROJECT POINT OF VIEW}

RobAFIS is organized as a project in which various stakeholders are involved. Each one has its own expectations, and well-defined role and contribution, as done in a real industrial organization for an acquisition project.

\subsection{ORGANISATION POINT OF VIEW}

\subsubsection{Competition management}

The competition contracting authority remains the same every year. It is ensured by the "Training and Skills" AFIS Technical Committee and Jean-Claude Tucoulou, RobAFIS permanent manager. This contracting authority is in a "client" position for the competing teams, and is a "supplier" for AFIS members and for all those interested in systems engineering education. To that end, the contracting authority has developed in 2010 a generic repository codifying the RobAFIS operation and facilitating the annual work of organizing committees. For each new edition, it proposes a host institution for the final, sets up the organizing committee and operates feedbacks to continuously improve the generic repository.

The competition prime contractor is ensured by the RobAFIS organizing committee, supported by the assessment jury, as well as all those involved in the event logistics and especially in the final phase. Its primary objectives are the definition of the overall schedule, the specification of the robot and its environment, the feasibility verification, and the competition repository writing and dissemination.

\subsubsection{Competition participation}

The competing contractors are all teams involved in the competition, participating in the development of a robot-solution and in the final phase of the competition.

\section{ROBAFIS: A STRUCTURED ENGINEERING APPROACH IN A PROJECT FRAMEWORK}

The competition is subject to various phases: prior registration, development and implementation, free trials, configuration audit, operational validation, and project presentation.

REGISTRATION PHASE: the Organizing Committee develops and disseminates the competition repository which includes:

competition rules, including participation conditions and overall schedule;

- $\quad$ specifications applicable to the system to be done and its operational environment;

- Development Document template giving the development document structure and the deliverables packaging.

In a pedagogical concern, this phase reproduces current practices of contractual relationships between a contracting authority, a prime contractor and its first-tier cooperating contractors.

DEVELOPMENT AND PROTOTYPE IMPLEMENTATION: At the end of the development phase, each team provides a complete development document, consistent with the Robafis Development Document model. For the robot prototype (Figure 1), participants use only a LEGO® kit, provided by the RobAFIS Organizing Committee for equity purposes regarding components supply. 


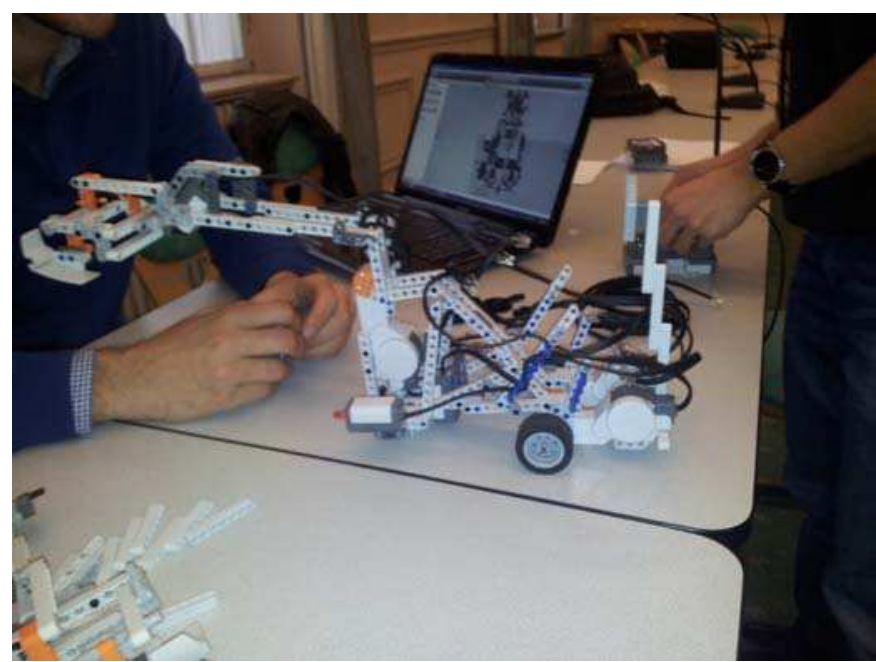

Figure 1: Engineering phase

FINAL (PART I): CONFIGURATION AUDIT: A group of three persons, external to the development team, has a limited time to assemble the robot using the configuration proposed in the development file. This operation is supervised by the jury who ensures compliance with the development document.

FINAL (PART II): TESTS AND IN SITU VERIFICATION: Each team has access to the assessment area during a limited time, to make in situ free trials and functional verifications. These tests are conducted without public, except members of the Organizing Committee. The team has the opportunity to modify the configuration of the product, but any change must be traced and discussed during the project audit.

FINAL (PART III): OPERATIONAL VALIDATION: The qualification has the dual purpose of assessing the robot performance in an operational situation (Figure 2) and in a confrontation with opponents. This is the key step in the operational evaluation. The objective is to evaluate the functional coverage completeness of each solution and to compare the mission execution speed of competing solutions.

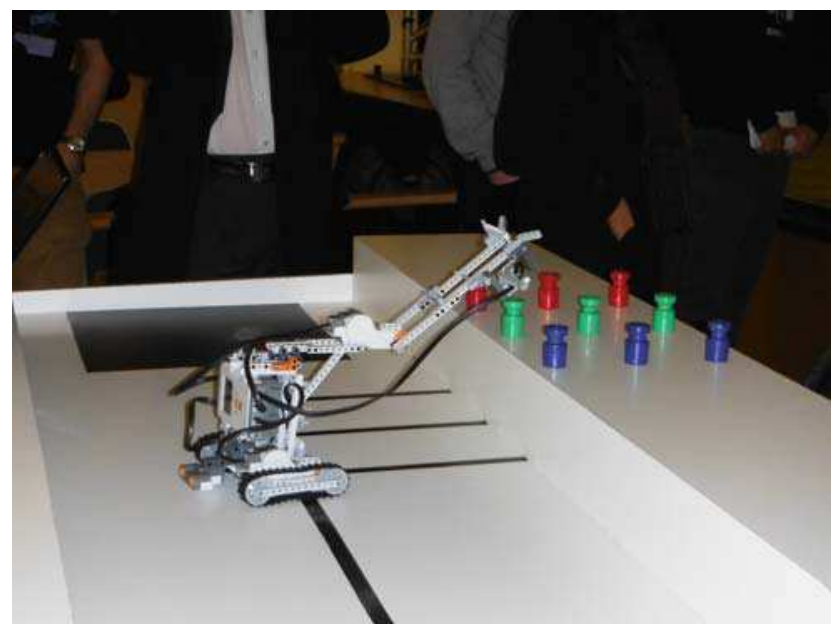

Figure 2: Deployment phase

FINAL (PART IV): PROJECT AUDIT: The project presentation is a feedback done after the operational evaluation. The objective is to explain success reasons and to investigate the possible difficulties and technical problems encountered.

\section{THE CONTRIBUTION OF DOCUMENT AND PHYSICAL DELIVERABLE DRIVEN SYSTEMS ENGINEERING}

Systems Engineering education relies on the acquisition of know-hows, based on methods and associated tools. Regarding ISO 15288 [4] standard, these know-hows enable technical processes activities, implemented using project processes activities in a broader context, the company related business processes activities. The overall aim is to achieve a system, result of acquisition and supply processes.

The framework proposed by the standard does not really structure the sequencing and planning of activities and processes leading to an orderly realization of activities and project deliverables. The principle 
proposed for RobAFIS is to provide a development repository formalizing documentary deliverables, which structured architecture guides processes and activities implementation, until the final stage of solution making, its validation and its participation in a customer review. In this sense, we can consider that we propose to achieve a deliverable driven engineering.

\title{
7. PURPOSE OF THE DEVELOPMENT DOCUMENT
}

This set framework guides teams in specifying the expectations for each elementary deliverable composing the Development Document. This document has three objectives for which students are particularly aware and guided throughout the operation:

Participate in the solution elaboration

This document is built up gradually during development, not a posteriori as a documentary formalization of the prototype solution developed experimentally. It allows any time sharing of data between project stakeholders, as acquired during development.

Control the configuration of the developed solution

This document must contain study and definition data needed to identify the development result, for a definition deemed complete and justified, manufacturable, verifiable, operational, testable, reparable and removable.

Document the project

This document is first established for the development team, to enable them to record and share data, from stakeholder requirements to the justified solution. It helps, when asked in the contract, to share data with the customer (prime contractor) for its own needs. Above all, it allows for the company developing this product, to ensure technical archives:

- If the project achievement is long-term and there is a need to ensure continuity with the resources (skills) that change (turnover); scratch";

- If the project is stopped and must return later with another team to continue without "starting from

- To capitalize on project achievements and to reuse results for future products developments (essential for product lines and derivatives treatments).

\section{DEVELOPMENT DOCUMENT ARCHITECTURE [5]}

\author{
1. Requirement referential (Deliverable 10) \\ 2. Architectural design (Deliverable 20) \\ 3. Reference configuration (Deliverable 30) \\ 4. Justification of architecture choices and definitions (Deliverable 40) \\ 5. Integration, Verification, Validation Plan (Deliverable 50) \\ 6. Maintainability study and maintenance definition (Deliverable 60) \\ 7. Project management (Deliverable 70) \\ 8. Assembly and verification instructions (Deliverable 80)
}

\section{BEST PRACTICIES FOR ENGINERING QUALITY}

- R1: The analysis of the operational environment and the related systems, source of requirements and constraints complementary to those included in the initial functional specifications.

- $\quad$ R2: The study of the functional architecture, an essential step for the requirement analysis and the physical architecture definition.

- R3: The search for candidate architectures and the justified choice of the selected one.

- R4: Performance allocation to functions, subsystems and elementary components, with values and tolerances including component characteristic dispersions.

- R5: A comprehensive requirement repository applicable to the system and its constituents, enriched by requirements identified during the design and applicable to the higher and system levels.

- R6: The realization of a robust solution incorporating functioning margins able to absorb dispersions related to specific constituents or resulting from the integration.

- R7: A justification guaranteeing the ability to achieve the mission, for all scenarios and for implementation boundary conditions.

- R8: The integration of the support system engineering in the system-of-interest engineering. 


\section{PERSPECTIVES}

The use of yearly feedbacks improves the competition and strengthens each time a little more educational aspect of the operation. Since 2007, the RobAFIS competition repositories and development files provided by teams are available as examples in the member area of the AFIS web site [2], in order to be viewed and analyzed by the students and teachers.

RobAFIS is increasingly used by teachers as an example (model) included in training curriculums, allowing students to apply knowledge and expertise learned, an essential condition to assess their ability to implement them. This is the case from the beginning of the competition for master degrees and engineering schools. New appropriate deployments are expected in 2014 for high schools, preparatory classes and technician level training.

\section{REFERENCES}

[1] Fiorèse S. and Meinadier J.-P. (Eds.), 2012. To discover and understand Systems Engineering (in french). Cépaduès. ISBN: 978-2364930056

[2] RobAFIS workspace on the AFIS web site http://www.afis.fr.

[3] RobAFIS dedicated web site: $h$ ttp://www.robafis.fr.

[4] ISO/IEC 15288 - System and software engineering - system life cycle processes

[5] Development repository, downloadable from http://www.robafis.fr 